\title{
Research
}

\section{Epidemiology of adult overweight recording and management by UK GPs:}

\author{
a systematic review
}

\begin{abstract}
Background

Primary care guidelines for managing adult overweight/obesity recommend routine measurement of body mass index (BMI) and the offer of weight management interventions. Many studies state that this is rarely done, but the extent to which overweight/obesity is recognised, considered, and documented in routine care has not been determined.
\end{abstract}

\section{Aim}

To identify the epidemiology of adult overweight documentation and management by UK GPS.

\section{Design and setting}

A systematic review of studies since 2006 from eight electronic databases and grey literature.

\section{Method}

Included studies measured the proportion of adult patients with documented BMI or weight loss intervention offers in routine primary care in the UK. A narrative synthesis reports the prevalence and pattern of the outcomes.

\section{Results}

In total, 2845 articles were identified, and seven were included; four with UK-wide data and three with regional-level data. The proportion of patients with a documented BMI was $58-79 \%$ (28-37\% within a year). For overweight/ obese patients alone, $43-52 \%$ had a recent $\mathrm{BMI}$ record, and $15-42 \%$ had a documented intervention offer. BMI documentation was positively associated with older age, female sex, higher BMI, coexistent chronic disease, and higher deprivation.

\section{Conclusion}

$\mathrm{BMI}$ is under-recorded and weight loss interventions are under-referred for primary care adult patients in the UK despite the obesity register in the Quality and Outcomes Framework (QOF). The review identified likely underserved groups such as younger males and otherwise healthy overweight/ obese individuals to whom attention should now be directed. The proposed amendmen to the obesity register QOF could prompt improvements but has not been adopted for 2017

\section{Keywords}

body mass index; general practice; obesity primary health care; weight recording.

\section{INTRODUCTION}

Most obese and overweight people in the UK state that they actively want to lose weight and would welcome advice from their doctor, but only $42 \%$ of obese adults report ever having received weight management advice from a healthcare professional.1,2 National Institute for Health and Care Excellence (NICE) guidelines recommend routine identification of obesity in primary care including the use of body mass index (BMI) as a practical estimate of adiposity in adults., ${ }^{3,4}$ Around three-quarters of patients see their GP at least once a year and obese individuals are proportionately higher users of care. ${ }^{5}$

There is evidence that doctors are inaccurate when asked to estimate the weight of patients $\mathrm{s}^{6-10}$ or even when taking anthropometric measurements that should be objective. ${ }^{11}$ In a UK study requiring GPs to estimate patients' BMI from photos, all underestimated and estimations worsened as patient BMI increased. ${ }^{12}$ Although lack of recognition may play a role in underdocumentation of BMI, some studies report lower rates of documentation than rates of self-report of weight discussion or diagnosis in a given consultation.13,14 Lack of documentation does not necessarily mean lack of recognition, but may reflect lack of weight prioritisation or intent to offer management. The documentation of a diagnosis of overweight or obesity itself in the patient's record is important as it is associated with the patient's receipt of interventions and weight management. 15,16

JC McLaughlin, MBChB, MSc, public health specialty registrar; K Hamilton, MRCP, public health specialty registrar, South West Public Health Training Programme; R Kipping, MA, MSc $\mathrm{PhD}, \mathrm{FFPH}, \mathrm{PGCE}$, senior research fellow, School of Social and Community Medicine, University of Bristol, Bristol.

\section{Address for correspondence}

Joanna C McLaughlin, post c/o Dr Ruth Kipping, School of Social and Community Medicine.
GP intervention for weight management has been shown to be effective and acceptable to patients even when it is extremely brief. ${ }^{17}$ The QOF (Quality and Outcomes Framework) is a voluntary incentive programme that financially rewards GP practices in England for provision of "quality care' with points assigned for performance against various indicators. In the 2015-2016 QOF, all practices in England received the points available for the stated QOF of establishing and maintaining a register of patients aged $\geq 18$ years who have a recorded $B M I$ of $\geq 30$ within the previous 12 months.'18 The registers indicated an adult obesity prevalence of $9.5 \%$. In contrast, the most recent (2014) Health Survey for England survey showed a considerable discrepancy, with $24 \%$ of males and $27 \%$ of females aged $>16$ years being obese. Some of this difference can be accounted for by any patient not having been seen in the previous 12 months being omitted from the register, but as obese patients require more health services $-74 \%$ have a comorbidity and at least three-quarters of the whole population see their GP each year ${ }^{5,19}$ - it is likely that the difference cannot be accounted for by this alone. As it has not been determined how complete and accurate each obesity register is, the register data are limited in gauging GPs' success in identifying and recording their patients' BMI. NICE proposed an additional obesity QOF indicator: 'The percentage of patients aged 18 or over ... who have had a record of a BMI being calculated

University of Bristol, Canynge Hall, 39 Whatley Road, Bristol, BS8 2PS, UK

E-mail: joannamclaughlinanhs.net

Submitted: 3 April 2017; Editor's response: 15 May 2017; final acceptance: 21 May 2017. (CBritish Journal of General Practice This is the full-length article (published online 29 Aug 2017) of an abridged version published in print. Cite this version as: Br J Gen Pract 2017; DOI: https://doi.org/10.3399/bjgp17X692309 


\section{How this fits in}

Adult overweight/obesity documentation or management by UK GPs has not been objectively quantified. This systematic review shows that around half of overweight/obese patients had a recent body mass index (BMI) record. The proportion of patients with a documented offer of weight loss intervention varied widely from $15 \%$ to $42 \%$. The proposed Quality and Outcomes Framework indicator of patients aged 18 or over ... who have had a record of a BMI being calculated in the preceding 5 years' could prompt improvements.

in the preceding 5 years land after their $18^{\text {th }}$ birthday)', but this has not been adopted in 2017.20 QOF has an uncertain future; already abandoned by Scotland, there are suggestions that England may follow suit. ${ }^{21}$

Many qualitative studies have been published highlighting the numerous barriers and difficulties that GPs feel they face in tackling obesity in primary care, including raising the issue with patients. ${ }^{22,23}$ There is, however, no clear source of quantitative data on the decisions taken by GPs faced with an overweight/obese patient in routine appointments, nor for the proportion and type of overweight/obese patients who are identified and documented as such.

In recognition of this gap in knowledge, this systematic review aimed to identify, collate, report, and interpret the available quantitative data on documentation of adult overweight and obesity by GPs in the UK.

\section{METHOD}

\section{Search strategy}

A systematic search using a predefined search protocol lavailable from authors on request) was carried out in June 2016. The following databases were searched: MEDLINE, EMBASE, CINAHL Plus, ASSIA, HMIC, BNI, Cochrane Library, and the Index to Theses. Limits were placed on all searches to English-language articles and to exclude articles published before 2006, in recognition of the introduction of the obesity register QOF

All retrieved studies were saved to RefWorks reference manager software. Duplicates were removed. One author screened the titles, abstracts, and full text of articles to determine inclusion. A second author screened a random subset of $10 \%$ of the articles at each stage with discussion over any discrepancies. An inter- rater reliability score was calculated using Cohen's $\kappa$.

The secondary sources comprised hand searching of the reference lists and citations of key papers found in databases, and e-mail communication with key authors to request details of any further studies meeting the inclusion criteria.

\section{Inclusion criteria}

To be eligible for inclusion, the studies had to report quantitative data on an objective measure of GPs' documentation of routine recording/discussion/diagnosis of BMI/ weight/lifestyle advice/offering of weight loss intervention as a main outcome. Studies had to be set in primary care in the UK and the subjects were adults laged $\geq 16$ years). Studies reporting on only a narrow group of patients (for example, patients with diabetes) or on a specialised setting (for example, a weight management clinic) were not eligible for inclusion.

\section{Critical appraisal and data extraction}

A bespoke critical appraisal tool (Table 1) that incorporated all important aspects of study quality, irrespective of the mix of study designs to allow improved comparability between studies, was piloted and then applied to each paper by two authors individually. The quality assessment tool developed here is based on methodology used in other reviews, ${ }^{24-26}$ and the Critical Appraisal Skills Programme (CASP) recommended checklists for each different study type where available, in particular the Newcastle-Ottawa scale for cohort and case control studies. ${ }^{27}$ For cross-sectional studies the Joanna Briggs Institute tool for appraisal of analytical cross-sectional studies $^{28}$ and questions adapted from Guyatt et al's publications on descriptive and cross-sectional studies were used for guidance. ${ }^{29,30}$

A narrative synthesis was prepared for the papers that met the exclusion and inclusion criteria. Emphasis was placed on interpreting and presenting the heterogeneity between studies and the individual risk of bias present for each outcome measure.

\section{RESULTS}

The search strategy returned 2845 results through searches of the electronic databases, 208 of which were retained after screening the titles and abstracts for relevance to the review and removal of duplicate results (Figure 1). A further 16 results from additional sources, from hand searches of reference lists and citations of 
Table 1. Summary of quality assessment tool results

\begin{tabular}{|c|c|c|c|c|c|c|c|}
\hline \multirow[b]{3}{*}{ Year of publication } & \multicolumn{7}{|c|}{ Lead author } \\
\hline & \multirow{2}{*}{$\frac{\text { Artac }^{34}}{2013}$} & \multirow{2}{*}{$\begin{array}{c}\text { Bhaskaran }^{35} \\
2013\end{array}$} & \multirow{2}{*}{$\begin{array}{c}\text { Booth }^{32} \\
2015\end{array}$} & \multirow{2}{*}{$\begin{array}{c}\text { Booth }^{31} \\
2013\end{array}$} & \multicolumn{3}{|c|}{ Dalton $^{36}$ Goodfellow $^{37}$ Osborn ${ }^{33}$} \\
\hline & & & & & 2011 & 2016 & 2011 \\
\hline Rationale and aim clear? & $\mathrm{x}$ & $x$ & $x$ & $x$ & $x$ & $x$ & $x$ \\
\hline Appropriate study design? & $x$ & $x$ & $\mathrm{x}$ & $x$ & $\mathrm{x}$ & $x$ & $x$ \\
\hline Baseline demographics of subjects given? & $x$ & & $x$ & $x$ & $x$ & $x$ & $x$ \\
\hline $\begin{array}{l}\text { Population choice, representative of: } \\
\text { UK primary care patients nationally } \\
\text { UK primary care patients in a local area } \\
\text { A specific group } \\
\text { Not specified }\end{array}$ & $x$ & $x$ & $x$ & $x$ & $x$ & $x$ & $x$ \\
\hline Predefined sampling frame? & $x$ & $x$ & $x$ & $x$ & $x$ & $x$ & $x$ \\
\hline $\begin{array}{l}\text { Sampling type: } \\
\text { Census/100\% sample } \\
\text { Random } \\
\text { Systematic } \\
\text { Convenience } \\
\text { Not specified }\end{array}$ & $x$ & $x$ & $x$ & $x$ & $x$ & $x$ & $x$ \\
\hline Setting and location of recruitment identified? & $x$ & $x$ & $x$ & $x$ & $\mathrm{x}$ & $x$ & $x$ \\
\hline Applied equally to all subjects? & $x$ & $x$ & $x$ & $x$ & $x$ & & $x$ \\
\hline Validated/standardised extraction technique? & $x$ & & & & $x$ & $x$ & \\
\hline Data from quality-controlled database of secure records? & $\mathrm{x}$ & $\mathrm{x}$ & $x$ & $x$ & $x$ & $\mathrm{x}$ & $x$ \\
\hline Time period included clear (post-QOF data identified)? & $x$ & $x$ & $x$ & $x$ & $x$ & $x$ & $x$ \\
\hline Clearly defined outcome measures, for example, BMI-defined obesity & $x$ & $x$ & $x$ & $x$ & $x$ & $x$ & \\
\hline Primary outcome was BMI or calculable BMI record & $\mathrm{x}$ & $\mathrm{x}$ & & $\mathrm{x}$ & $\mathrm{x}$ & & $\mathrm{x}$ \\
\hline Medical codes/other documentation included & & & $x$ & $x$ & $\mathrm{x}$ & $x$ & \\
\hline Predictive factors, for example, age, sex, practice detailed & $\mathrm{x}$ & $\mathrm{x}$ & $x$ & $x$ & $\mathrm{x}$ & $x$ & $x$ \\
\hline Statistical methods used appropriately & $\mathrm{x}$ & $\mathrm{x}$ & $x$ & $\mathrm{x}$ & $x$ & $x$ & $\mathrm{x}$ \\
\hline Results presented clearly (sufficient data presented) & $x$ & $x$ & $x$ & $x$ & $\mathrm{x}$ & & \\
\hline Interpretation takes into account sources of bias/imprecision (exclusions, missing data) & $x$ & $x$ & $x$ & $x$ & $\mathrm{x}$ & $x$ & $x$ \\
\hline Interpretation is made in the context of current evidence & $x$ & $x$ & $x$ & $x$ & $x$ & $x$ & $x$ \\
\hline $\begin{array}{l}\text { Generalisability of results: } \\
\text { All UK adults } \\
\text { All UK primary care adult patients } \\
\text { All overweight/obese UK primary care patients } \\
\text { Patients in a local region } \\
\text { Not clear to whom generalisable }\end{array}$ & $x$ & $x$ & $x$ & $\mathrm{x}$ & $x$ & $x$ & $x$ \\
\hline
\end{tabular}

key papers, were identified and subjected to further screening for suitability. Responses were received from four of the key authors, whose guidance had been requested by e-mail on any further studies suitable for inclusion in the review. No further studies were identified. Full-text versions of the papers were retrieved at this stage. Seven studies met the inclusion and exclusion criteria.

The Cohen's $\kappa$ was 1.00 for agreement between the two authors at both the title screening and full-text stages.

Of the seven studies that were included in the review (Table 2): three ${ }^{31-33}$ were retrospective cohort studies based on large primary care databases, three ${ }^{34-36}$ were cross-sectional/descriptive in design using data from a primary care database or regional GP practice patient records, and the final study ${ }^{37}$ was a cluster randomised controlled trial within a further region of GP practices. The quality assessment tool allows visual comparison of the areas of difference and similarity in quality across the papers (Table 2). Table 3 presents the results of the outcome measures for each study.

\section{Proportion of patients with a documented BMI}

The proportion of adult patients with any record of $\mathrm{BMI}$ was $79 \%$; however, when the 


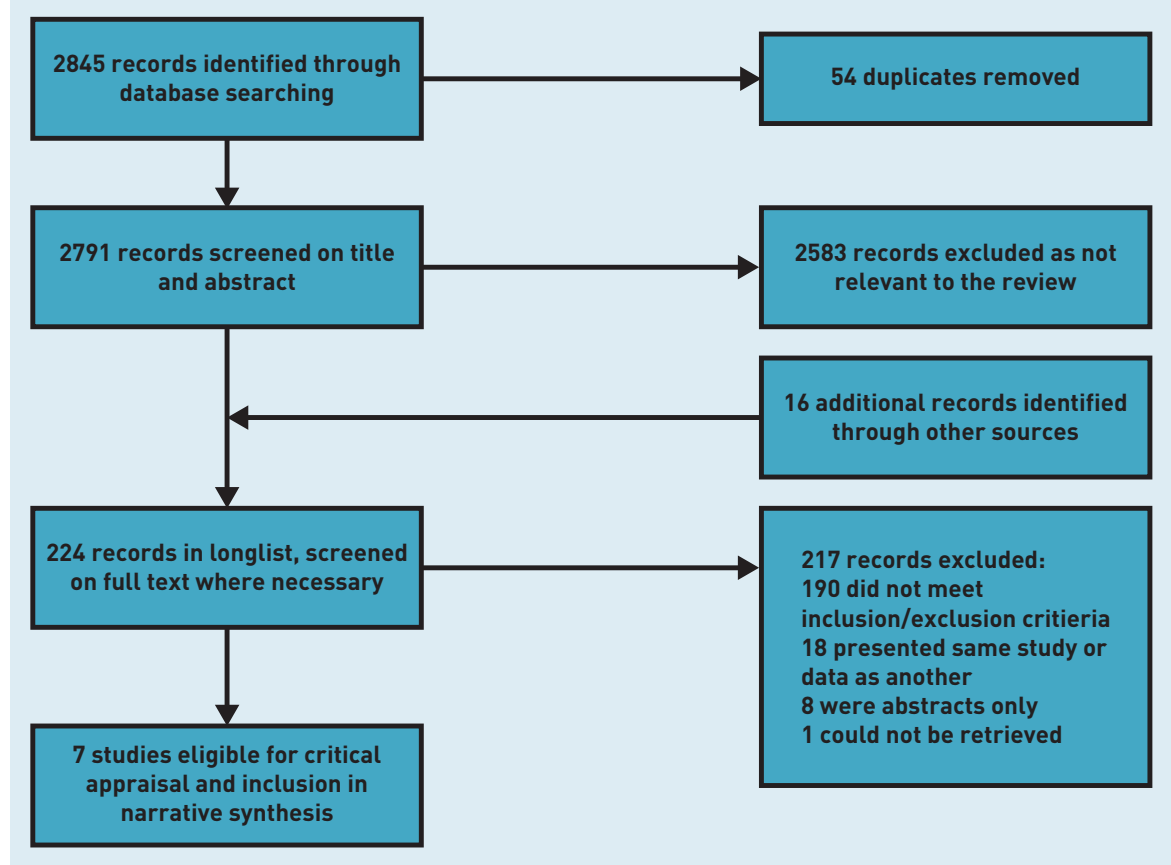

Figure 1. Flowchart of selection process. recording period was recent, this decreased to between $57.9 \%$ and $79.3 \%$ for males and $60.7 \%$ and $67.6 \%$ for females when considering the previous 5 years, ${ }^{34,36}$ and to $52 \%$ for the previous 3 years. ${ }^{35}$ Further, when $\mathrm{BMI}$ documentation was considered within 11-12 months, which is closer to the QOF register, this ranged from $27.6 \%$ to $45.6 \%$ for males and $37.3 \%$ to $52.1 \%$ for females. $31,33,37$

\section{Proportion of patients with a documented} offer of a weight management intervention The offer of a weight management intervention was measured in two studies: $15.1 \%$ of overweight or obese adults were offered an intervention in one 11-month period studied; ${ }^{37}$ in another study the proportions varied greatly by level of overweight and obesity, with approximately $40 \%$ and $41.9 \%$, respectively, of morbidly obese males and females being offered an intervention, while this reduced to $15.8 \%$ and $19.8 \%$ of non-morbidly obese males and females, and $10 \%$ of overweight patients. ${ }^{32}$

\section{Table 2. Studies meeting inclusion and exclusion criteriaa}

\begin{tabular}{|c|c|c|}
\hline Study & Primary care subjects ${ }^{b}$ & Study's design and relevance \\
\hline $\begin{array}{l}\text { Artac, } 2013^{34} \\
\text { Evaluation of a National Cardiovascular } \\
\text { Risk Assessment Programme (NHS Health Check) } \\
\text { PhD thesis }\end{array}$ & $\begin{array}{l}\text { Hammersmith and Fulham (London, UK) } \\
\text { GP practices } N=42306\end{array}$ & $\begin{array}{l}\text { Cross-sectional study of electronic medical records } \\
\text { of patients eligible for NHS Health Checks, } \\
\text { describes BMI recording completeness }\end{array}$ \\
\hline $\begin{array}{l}\text { Bhaskaran et al, } 2013^{35} \\
\text { Representativeness and optimal use of body mass } \\
\text { index (BMI) in the UK Clinical Practice Research } \\
\text { Datalink (CPRD) }\end{array}$ & $\begin{array}{l}\text { UK-wide database; Clinical Practice } \\
\text { Research Datalink (CPRD) N=325 } 948\end{array}$ & $\begin{array}{l}\text { Descriptive study of completeness of BMI recording } \\
\text { for a sample of }>16 \text {-year-olds within this primary } \\
\text { care database }\end{array}$ \\
\hline $\begin{array}{l}\text { Booth et al, } \mathbf{2 0 1 5 ^ { 3 2 }} \\
\text { Access to weight reduction interventions for } \\
\text { overweight and obese patients in UK primary care: } \\
\text { population-based cohort study }\end{array}$ & $\begin{array}{l}\text { UK-wide database; Clinical Practice } \\
\text { Research Datalink (CPRD) N=91 } 413\end{array}$ & $\begin{array}{l}\text { Retrospective cohort study of recorded weight } \\
\text { management intervention offers for a sample } \\
\text { of overweight/obese patients within this } \\
\text { primary care database }\end{array}$ \\
\hline $\begin{array}{l}\text { Booth et al, } 2013^{31} \\
\text { Epidemiology of clinical body mass index recording } \\
\text { in an obese population in primary care: a cohort study }\end{array}$ & $\begin{array}{l}\text { UK-wide database; General Practice } \\
\text { Research Database (GPRD) } \\
N=40000-46000 \text { per year }\end{array}$ & $\begin{array}{l}\text { Retrospective cohort study of the epidemiology of } \\
\text { recording of BMI for a sample of obese patients } \\
\text { within this primary care database }\end{array}$ \\
\hline $\begin{array}{l}\text { Dalton et al, } 2011^{36} \\
\text { Implementation of the NHS Health Checks } \\
\text { programme: baseline assessment of risk factor } \\
\text { recording in an urban culturally diverse setting }\end{array}$ & $\begin{array}{l}\text { North West London (UK) GP practices } \\
\text { participating in pilot NHS Health Checks } \\
\text { Programme } N=21510\end{array}$ & $\begin{array}{l}\text { Cross-sectional study of electronic medical records } \\
\text { of patients eligible for NHS Health Checks, } \\
\text { describes BMI recording completeness }\end{array}$ \\
\hline 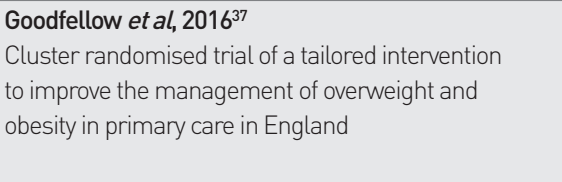 & East Midlands (UK) GP practices N=32079 & $\begin{array}{l}\text { Cluster randomised controlled trial of an intervention } \\
\text { to improve obesity management in primary care. } \\
\text { Data from the control arm describe BMI recording } \\
\text { and interventions offered to overweight/obese } \\
\text { patients aged }>16 \text { years in normal practice }\end{array}$ \\
\hline $\begin{array}{l}\text { Osborn et al, } 2011^{33} \\
\text { Inequalities in the provision of cardiovascular } \\
\text { screening to people with severe mental illnesses } \\
\text { in primary care. Cohort study in the United Kingdom } \\
\text { THIN Primary Care Database } 2000-2007\end{array}$ & $\begin{array}{l}\text { UK-wide database; The Health Improvement } \\
\text { Network (THIN) N=95512 }\end{array}$ & $\begin{array}{l}\text { Retrospective cohort study describing BMI } \\
\text { recording in patients aged }>18 \text { years within the } \\
\text { database with serious mental illness and for } \\
\text { controls (the group of interest here) }\end{array}$ \\
\hline
\end{tabular}

a Where subjects are described as overweight or obese this refers to a BMI of $\geq 25$ and $\geq 30 \mathrm{~kg} / \mathrm{m}^{2}$, respectively. ${ }^{b} \mathrm{~N}$ refers to the number of subjects in the study relevant to the review research question. $B M I=$ body mass index. 


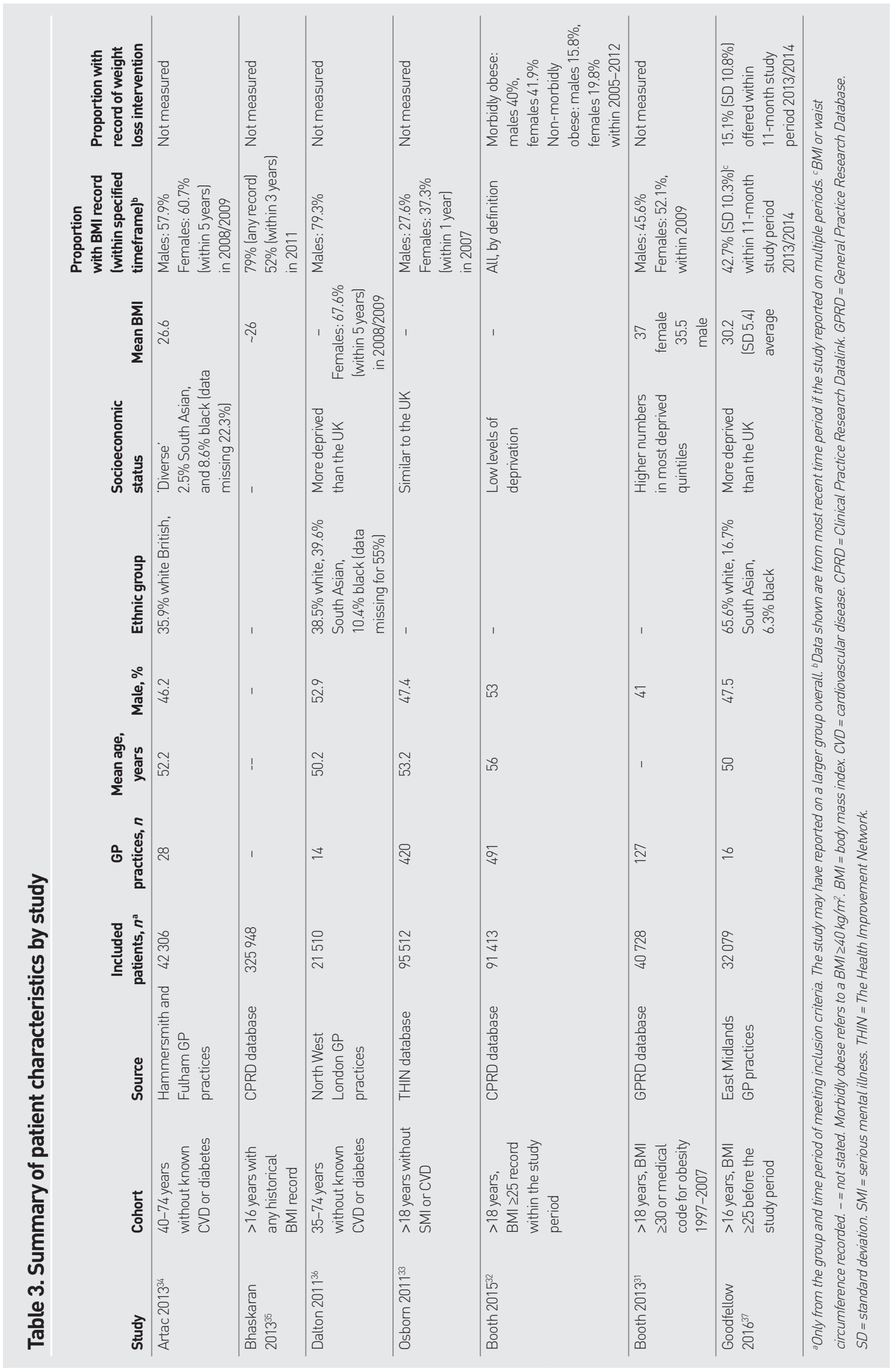




\section{Patient factors associated with the outcomes}

All the studies described a pattern of association between BMI recording and increasing patient age, and also with female sex. Several studies showed higher rates of $\mathrm{BMI}$ recording for older patients, higher $\mathrm{BMI}$, or comorbidities, and suggested that this was because these groups tend to consult primary care practitioners more often. Five studies ${ }^{31-34,36}$ reported that BMI recording or weight loss intervention offer rates were associated with increasing deprivation at the patient level (generally based on postcode).

\section{DISCUSSION}

\section{Summary}

This systematic review included seven studies in total: four large UK-wide studies and three regional studies with either a BMI record or an offer of weight loss intervention documented for adult patients in routine primary care consultations in the UK. The general proportion of adult patients with a documented BMI was reported at 58-79\% over the longer term, and $28-37 \%$ where the record was within 12 months. The proportion of overweight/obese patients with a recent documented BMI record was $43-52 \%$. The proportion of overweight/obese adult patients with a documented offer of weight loss intervention was reported in a less consistent manner and ranged from $15 \%$ to $42 \%$. Regional settings of the data collection and different timeframes for the intervention offer may account for the wide variation

Higher rates of documentation were associated with patients' older age, female sex, higher BMI, coexistent chronic disease, and higher deprivation. This was attributed to primary care consultation rates being higher for these groups, ${ }^{38,39}$ leading to increased opportunity for recognition and recording.

\section{Strengths and limitations}

The comprehensive nature of the search strategy, with the inclusion of all study designs, is a strength of the study. Further, the collection of data from patient records allowed comparability among studies. Patient electronic health records, particularly within quality-controlled research databases, are a strong source of data for primary care research but they do not cover verbal exchanges or elements such as patient refusal.

Although the review included studies with adult patients served by the UK primary care system in the last 10 years, the external validity for some studies is limited by those that were regional databases or where studies only included overweight/ obese patients and differing lengths of time for which documentation in the patient record was measured. A limitation of the review is that the classification of an "up-todate' BMI record varied among studies. Although the 2006 QOF indicator implies that the period of interest is 12 months, there is no consensus in the literature over how recent a BMI record needs to be to be representative. To deal with this variability, this review has reported on categories of $\mathrm{BMI}$ record recency. A further limitation is that it is possible that participants in longitudinal studies were not representative of the general primary care adult population, and awareness of being studied could have altered the behaviour of the primary care team or patients involved in the control arms.

The systematic review aimed to draw inferences for the whole UK adult primary care patient population, but it is challenging to account for adults who either are not registered with a GP or who choose not to consult their GP. Estimating the number of unregistered adults in the UK is not straightforward. ${ }^{40}$

\section{Comparison with existing literature}

The results from the synthesis of the included papers in this review show coherence with the results of publications that have presented data before introduction of the QOF in 2006. In 2003, 42\% of obese adults had a BMI recorded and $40 \%$ had been given weight management advice in a primary care study. ${ }^{41}$ A cross-sectional study from 2004 on the electronic GP records of 435102 patients in England showed that $56.8 \%$ of males and $69.3 \%$ of females had a BMI record, supporting the finding of this review that females have higher rates of recording. ${ }^{42}$

This review did not include data from more subjective outcome measures such as patient self-report of weight loss discussion, but a study of this nature found that less than one-third of overweight or obese patients reported that they had received lifestyle advice for weight management from their $\mathrm{GP}_{4}^{43}$ a figure within the range of the proportion of patients with a documented weight loss intervention offer in this review. A small study of 42 videotaped routine consultations by GPs in Scotland showed that weight management was rarely mentioned, even when the patient was overweight or obese. ${ }^{44}$ 


\section{Implications for research and practice}

The growing burden of obesity on primary care and the discrepancies between data sourced in primary care and accepted measures of 'true prevalence' of overweight/ obesity in the UK support the case for changes to policy and practice in this area.

A large, UK-wide observational study to gather contemporary data from routine consultations between adult patients and all members of the primary care team would be invaluable in considering the uncertainties surrounding undocumented recognition, discussion, and intervention for overweight/obesity, including an exploration of the role of patient refusal to be weighed or engage in weight management.

Future studies would benefit from closer integration with the policy context, for example, consistent use of outcome measures that reflect the values and recommendations of the NICE guidelines and QOF indicators.

Structured recording of patient BMI and interventions offered could improve the overall prevalence of recognition of overweight/obesity and decrease the inequalities that likely result from the differences in practice between patient groups. The proposed QOF indicator addition - 'The percentage of patients aged
18 or over ... who have had a record of a BMI being calculated in the preceding 5 years land after their $18^{\text {th }}$ birthdayl' - may prompt improvements, although the obesity register QOF has remained unchanged for 2017 and the future of QOF in England is uncertain generally. Complementary interventions may include electronic prompts to record patients' weight at registration or yearly intervals and facilities for patients to submit their own weight record remotely. Attention should be paid to the patient groups revealed by this review to be most underserved, such as younger males and overweight/obese individuals with no comorbidities.

Qualitative research suggests that some GPs believe patients carry the responsibility for their obesity and that primary care is not the appropriate source of intervention, ${ }^{45,46}$ and GP motivation to consider weight is damaged by a real and perceived lack of availableand effective interventions. ${ }^{5,32,47}$ This presents a challenge to the improvement of weight management's integration into a primary care system already struggling with capacity. In contrast, public health and obesity experts view obesity as a chronic disease, and maintain that primary care healthcare professionals are vital in dealing with the problem. ${ }^{48}$
Registrars. Ruth Kipping works in the Centre for the Development and Evaluation of Complex Interventions for Public Health Improvement (DECIPHer), a UKCRC Public Health Research Centre of Excellence. Joint funding (MR/KO232331/1) from the British Heart Foundation, Cancer Research UK, Economic and Social Research Council, Medical Research Council, the Welsh Government, and the Wellcome Trust, under the auspices of the UK Clinical Research Collaboration, is gratefully acknowledged. The views expressed in this paper are those of the authors and not necessarily any of the funding bodies listed here.

\section{Ethical approval}

Ethical approval was not required for this systematic review methodology.

\section{Provenance}

Freely submitted; externally peer reviewed.

\section{Competing interests}

The authors have declared no competing interests

\section{Open access}

This article is Open Access: CC BY-4.0 licence (https://creativecommons.org/ licenses/by/4.0/).

\section{Discuss this article}

Contribute and read comments about this article: bjgp.org/letter 


\section{REFERENCES}

1. Jackson SE, Wardle J, Johnson F, et al. The impact of a health professional recommendation on weight loss attempts in overweight and obese British adults: a cross-sectional analysis. BMJ Open 2013; 3(11): e003693.

2. Duaso MJ, Cheung P. Health promotion and lifestyle advice in a general practice: what do patients think? J Adv Nurs 2002; 39(5): 472-479.

3. National Institute for Health and Care Excellence. Obesity: identification assessment and management. CG189. London: NICE, 2014. https://www.nice. org.uk/guidance/cg189/chapter/1-recommendations\#surgical-interventions laccessed 14 Jul 2017).

4. National Institute for Health and Care Excellence. Weight management lifestyle services for overweight or obese adults. PH53. London: NICE, 2014. https://www.nice.org.uk/guidance/ph53 laccessed 4 Jul 2017).

5. Mercer S. How useful are clinical guidelines for the management of obesity in general practice? Br J Gen Pract 2009; DOI: https://doi.org/10.3399/bjgp09X472917.

6. Fernandes CMB, Clark S, Price A, Innes G. How accurately do we estimate patients weight in emergency departments? Can Fam Physician 1999; 45: 2373-2376.

7. Anglemyer BL, Hernandez C, Brice JH, Zou B. The accuracy of visual estimation of body weight in the ED. Am J Emerg Med 2004; 22(7): 526-529.

8. Hall WL, Larkin GL, Trujillo MJ, et al. Errors in weight estimation in the emergency department: comparing performance by providers and patients. J Emerg Med 2004; 27(3): 219-224

9. Corbo J, Canter M, Grinberg D, Bijur P. Who should be estimating a patient's weight in the emergency department? Acad Emerg Med 2005; 12(3): 262-266.

10. Bloomfield R, Steel E, MacLennan G, Noble DW. Accuracy of weight and height estimation in an intensive care unit: implications for clinical practice and research. Crit Care Med 2006; 34(8): 2153-2157.

11. Sebo $P$, Haller DM, Pechère-Bertschi $A$, et al. Accuracy of doctors' anthropometric measurements in general practice. Swiss Med Wkly 2015; 145: w14115.

12. Robinson E, Parretti H, Aveyard P. Visual identification of obesity by healthcare professionals: an experimental study of trainee and qualified GPs. $\mathrm{Br} J \mathrm{Gen}$ Pract 2014; DOI: https://doi.org/10.3399/bjgp14X682285.

13. Post RE, Mainous AG, Gregorie SH, et al. The influence of physician acknowledgement of patients' weight status on patient perceptions of overweight and obesity in the United States. Arch Intern Med 2011; 171(4): 316-321.

14. Rose SA, Gokun Y, Talbert J, Conigliaro J. Screening and management of obesity and perception of weight status in Medicaid recipients. $J$ Health Care Poor Underserved 2013; 24(2 Suppl): 34-46.

15. Noel PH, Copeland LA, Pugh MJ, et al. Obesity diagnosis and care practices in the Veterans Health Administration. J Gen Intern Med 2010; 25(6): 510-516.

16. Bardia A, Holtan SG, Slezak JM, Thompson WG. Diagnosis of obesity by primary care physicians and impact on obesity management. Mayo Clin Proc 2007; 82(8): 927932

17. Aveyard $\mathrm{P}$, Lewis $\mathrm{A}$, Tearne $\mathrm{S}$, et al. Screening and brief intervention for obesity in primary care: a parallel, two-arm, randomised trial. Lancet 2016; 388(10059): 2492-2500.

18. Health and Social Care Information Centre. Quality and Outcomes Framework - prevalence, achievements and exceptions report: England, 2015-16. 2016. http://www.content.digital.nhs.uk/catalogue/PUB22266/qof-1516-rep-v2.pdf laccessed 14 Jul 2017)

19. British Medical Association. General practice in the UK background briefing April 2017. 2017. https://uww.bma.org.uk/-/media/files/pdfs/news\%20views\%20 analysis/press\%20briefings/general-practice.pdf?la=en (accessed 28 Jul 2017).

20. National Institute for Health and Care Excellence. New indicators to be added to the NICE QOF menu and amendments to existing QOF indicators. London: NICE, 2016. https://www.nice.org.uk/Media/Default/Standards-and-indicators/ indicators-general-practice-aug-16.pdf (accessed 18 Jul 2017).

21. Ashworth M, Gulliford MC. Funding for general practice in the next decade: life after QOF. Br J Gen Pract 2017; DOI: https://doi.org/10.3399/bjgp17X688477.

22. Blackburn M, Stathi A, Keogh E, Eccleston C. Raising the topic of weight in general practice: perspectives of GPs and primary care nurses. BMJ Open 2015; 5(8): e008546

23. Blane DN, Macdonald S, Morrison D, O'Donnell CA. Interventions targeted at primary care practitioners to improve the identification and referral of patients with co-morbid obesity: a realist review protocol. Syst Rev 2015; 4(1): 61.

24. Parry LL, Netuveli G, Parry J, Saxena S. A systematic review of parental perception of overweight status in children. J Ambul Care Manage 2008; 31(3): 253-268.

25. Thomson H, Thomas S, Sellstrom E, Petticrew M. The health impacts of housing improvement: a systematic review of intervention studies from 1887 to 2007. Am J Public Health 2009; 99(Suppl 3): s681-s692.
26. Taylor BJ, Dempster M, Donnelly M. Grading gems: appraising the quality of research for social work and social care. Br J Soc Work 2007; 37(2): 335-354.

27. Wells G, Shea B, O'Connell D, et al. The Newcastle-Ottawa Scale (NOS) for assessing the quality of nonrandomised studies in meta-analyses. Ottawa: Department of Epidemiology and Community Medicine, University of Ottawa, 2014. http://www.ohri.ca/programs/clinical_epidemiology/oxford.htm laccessed 18 Jul 2017)

28. Joanna Briggs Institute. The Joanna Briggs Institute reviewers' manual 2014 the systematic review of prevalence and incidence data. Adelaide: Joanna Briggs Institute, University of Adelaide, 2014. https://joannabriggs.org/assets/ docs/sumari/ReviewersManual_2014-The-Systematic-Review-of-Prevalenceand-Incidence-Data_v2.pdf (accessed 13 Jul 2017).

29. Guyatt G, Sackett D, Cook D. Users' guides to the medical literature. II. How to use an article about therapy or prevention. JAMA 1993; 270(21): 2598-2601.

30. Guyatt GH, Oxman AD, Vist GE, et al. GRADE: an emerging consensus on rating quality of evidence and strength of recommendations. BMJ 2008; 336(7650): 924-926.

31. Booth HP, Prevost AT, Gulliford MC. Epidemiology of clinical body mass index recording in an obese population in primary care: a cohort study. $J$ Public Health (Oxf) 2013; 35(1): 67-74

32. Booth HP, Prevost AT, Gulliford MC. Access to weight reduction interventions for overweight and obese patients in UK primary care: population-based cohort study. BMJ Open 2015; 5(1): e006642.

33. Osborn DP, Baio G, Walters K, et al. Inequalities in the provision of cardiovascular screening to people with severe mental illnesses in primary care. Cohort study in the United Kingdom THIN Primary Care Database 2000-2007. Schizophr Res 2011; 129(23): 104-110.

34. Artac M. Evaluation of a national cardiovascular risk assessment programme (NHS Health Check). London: Imperial College London, 2013. https://spiral. imperial.ac.uk/handle/10044/1/24725 laccessed 18 Jul 2017).

35. Bhaskaran K, Forbes HJ, Douglas I, et al. Representativeness and optimal use of body mass index (BMI) in the UK Clinical Practice Research Datalink (CPRD). BMJ Open 2013; 3: e003389.

36. Dalton AR, Bottle A, Okoro C, et al. Implementation of the NHS Health Checks programme: baseline assessment of risk factor recording in an urban culturally diverse setting. Fam Pract 2011; 28(1): 34-40.

37. Goodfellow J, Agarwal S, Harrad F, et al. Cluster randomised trial of a tailored intervention to improve the management of overweight and obesity in primary care in England. Implement Sci 2016; 11(1): 77.

38. Wang Y, Hunt $\mathrm{K}$, Nazareth I, et al. Do men consult less than women? An analysis of routinely collected UK general practice data. BMJ Open 2013; 3(8): e003320.

39. Hippisley-Cox J, Vinogradova Y. Trends in consultation rates in general practice 1995/1996 to 2008/2009: analysis of the QResearch ${ }^{\circledR}$ database. London: QResearch, Information Centre for Health and Social Care, 2009. http://www. content.digital.nhs.uk/catalogue/PUB01077/tren-cons-rate-gene-prac-95-0995-09-rep.pdf (accessed 10 Aug 2017).

40. Baker C. Population estimates \& GP registers: why the difference?2016 https://secondreading.uk/social-policy/population-estimates-gp-registerswhy-the-difference/ laccessed 10 Aug 2017).

41. Moore H, Summerbell CD, Greenwood DC, et al. Improving management of obesity in primary care: cluster randomised trial. BMJ 2003; 327(7423): 1085.

42. de Lusignan S, Hague N, van Vlymen J, et al. A study of cardiovascular risk in overweight and obese people in England. Eur J Gen Pract 2006; 12(1): 19-29

43. Booth AO, Nowson CA. Patient recall of receiving lifestyle advice for overweight and hypertension from their General Practitioner. BMC Fam Pract 2010; 11: 8 .

44. Laidlaw A, McHale C, Locke H, Cecil J. Talk weight: an observational study of communication about patient weight in primary care consultations. Prim Health Care Res Dev 2015; 16(3): 309-315.

45. Epstein L, Ogden J. A qualitative study of GPs' views of treating obesity. $\mathrm{Br} J$ Gen Pract 2005; 55(519): 750-754.

46. Henderson E. Obesity in primary care: a qualitative synthesis of patient and practitioner perspectives on roles and responsibilities. Br J Gen Pract 2015; DOI: https://doi.org/10.3399/bjgp15X684397.

47. Royal College of Surgeons. Commissioning guide: weight managment and assessment clinics (Tier 3). 2014. http://www.bomss.org.uk/wp-content/ uploads/2014/04/Commissioning-guide-weight-assessment-andmanagement-clinics-published.pdf (accessed 23 Jun 2017).

48. Boyce T, Peckham S, Hann A, Trenholm S. A pro-active approach. Health promotion and ill-health prevention. An inquiry into the quality of general practice in England. London: King's Fund, 2010. http://www.kingsfund.org.uk/ sites/files/kf/field/field_document/health-promotion-ill-health-prevention-gpinquiry-research-paper-mar11.pdf laccessed 13 Jul 2017). 